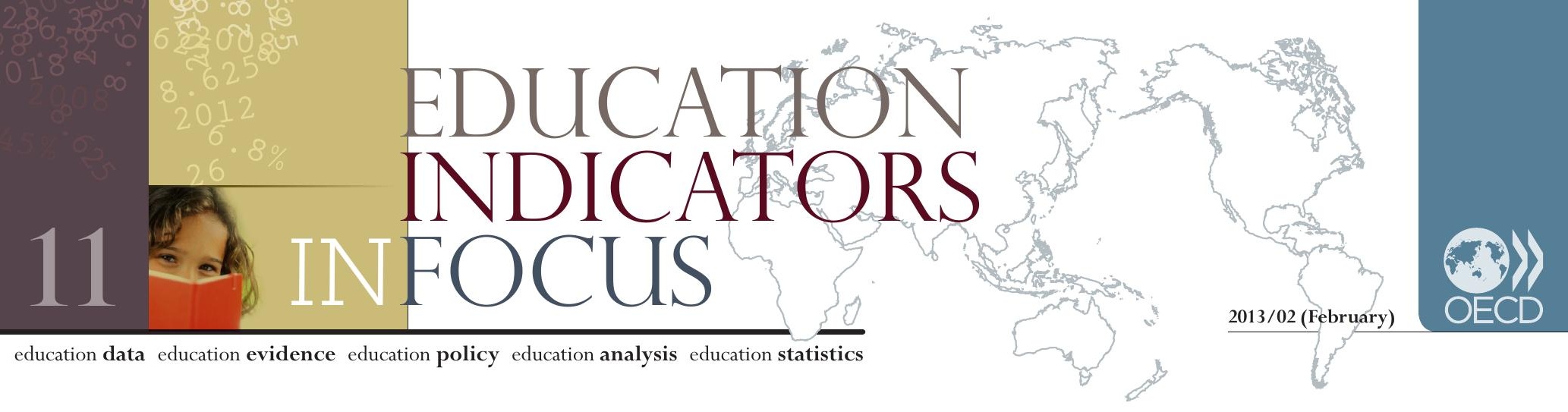

\title{
How do early childhood education and care (ECEC) policies, systems and quality vary across OECD countries?
}

- In many OECD countries, ECEC services have increased in response to a growing demand for better learning outcomes as well as growing female labour force participation. In recent years, however, the goals of ECEC policy have become more child-centred.

- Fifteen-year-old students who attended early childhood education (ECE) tend to perform better on PISA than those who did not, even after accounting for their socio-economic backgrounds.

- Improving access without giving due attention to the quality of ECEC services is not sufficient to secure good individual and social outcomes.

ECEC services have been expanding as part of labour market policies.

In a majority of OECD countries, ECEC policy has paralleled the evolution of female labour force participation. More and more women have entered salaried employment since the 1970s, reinforced by the rise of service- and knowledge-based economies. Because economic prosperity depends on maintaining a high employment/population ratio, bringing more women into the labour market has been a key driver of governments' interest in expanding ECEC services. In the 1970s and 1980s, European governments, in particular, put family and child care policies into place to help couples to have children and to ensure that it is feasible for women to combine work and family responsibilities (OECD, 2011; 2006).

However, ECEC policy is increasingly designed as education policy.

It is only recently that the goals of ECEC policy have been geared more towards enhancing child development and outcomes than to serving parental needs. Consequently, ECEC policy is often embedded into anti-poverty or educational equity measures, as inequalities in child outcomes are already present when children enter formal schooling, and are likely to grow over time. Today, many OECD governments see ECEC as a public investment and integrate ECEC services to ensure holistic and continuous child development. Coherent, high-quality ECEC services are used as an effective tool to help children build a strong foundation for life skills and, therefore, better life chances, especially for children from disadvantaged or immigrant backgrounds.

Early childhood education (ECE) covers all forms of organised and sustained centre-based activities - such as pre-schools, kindergartens and day-care centres - designed to foster learning and emotional and social development in children. These programmes are generally offered to children from the age of three.

Early childhood care (ECC) covers all centre-based day care that is provided outside the home in licensed centres. These services are most commonly referred to as nurseries, day-care centres, crèches, playschools and parent-run groups. Some countries also include family day care as part of ECC. It can be provided in a home setting, at the childminder's home or at the child's own home where a qualified or registered childminder looks after the child. ECC can be provided to children as early as from birth.

Early childhood education and care (ECEC) encompasses all forms of ECE and ECC services under an integrated system, which provides integrated pedagogical settings covering age zero or one to compulsory schooling age. 


\section{Many OECD countries have significantly increased the proportion of children} enrolled in ECE programmes in recent decades.

In recent decades, many countries have significantly increased the proportion of children enrolled in ECE programmes. In the majority of OECD countries, most children enter education well before the age of 5 , and more than three-quarters of 4-year-olds (79\%) are enrolled in ECE or ECEC programmes across OECD countries as a whole. However, enrolment rates vary from over 95\% in Belgium, France, Germany, Iceland, Italy, Japan, Luxembourg, Mexico, the Netherlands, New Zealand, Norway, Spain and the United Kingdom, at one end of the spectrum, to less than 60\% (but more than 30\%) in Australia, Canada, Finland, Greece, Poland and Switzerland, and to less than $30 \%$ in Turkey at the other end of the spectrum among OECD countries.

In Mexico and Poland, enrolment rates increased by more than 20 percentage points between 2005 and 2010 (see chart below).

Enrolment rates in early childhood and primary education at age 4 (2005 and 2010) Full-time and part-time pupils in public and private institutions

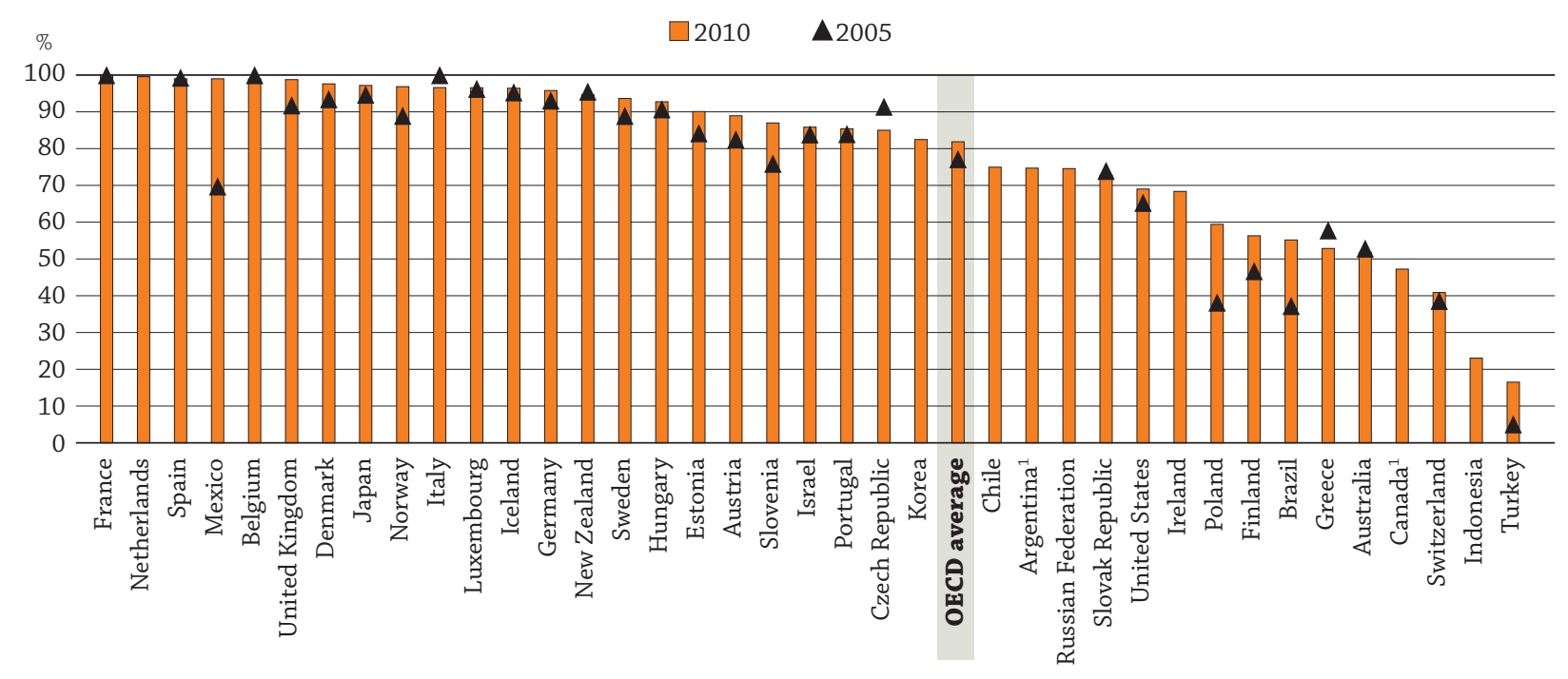

1. Year of reference 2009.

Countries are ranked in descending order of the enrolment rates of 4-year-olds in 2010.

Source: OECD. Argentina and Indonesia: UNESCO Institute for Statistics (World Education Indicators programme). Education at a Glance 2012: OECD Indicators, Indicator C2 (www.oecd.org/edu/eag2012).

\section{PISA results have shown that high-quality ECE can result in better outcomes} in the later stages of life. But the extent of its benefits heavily depends on the quality of the ECEC services.

A growing body of research recognises that ECEC can improve children's cognitive abilities and socio-emotional development, help create a foundation for lifelong learning, make children's learning outcomes more equitable, reduce poverty and improve social mobility from generation to generation (OECD, 2012a; 2012b). However, the degree to which ECEC can produce these benefits depends on the quality of the ECEC services. Increasing access to services without giving due attention to quality will not result in good child outcomes or long-term productivity benefits for society.

PISA results show that participation in ECE is strongly associated with reading performance at age 15, even after accounting for students' socio-economic backgrounds. PISA results also suggest that the relationship between ECE participation and later learning outcomes is the strongest in countries with certain "quality" features. The indicative quality indicators include child-staff ratio, the duration of programmes and public spending per child (OECD, 2010). 


\section{Indicators relating to learning and well-being environments, such as child-staff ratio and staff quality, affect children's learning outcomes.}

In the absence of direct measures of the quality of provision, the ratio of pupils to teaching staff is often used as a proxy to mesure quality in ECE (OECD, 2010). A large body of research has found that the lower the child-staff ratio is, the better the children perform in cognitive (mathematics and science) and linguistic (language, reading and word recognition) assessments.

On average, there are 14 pupils for every ECE teacher in OECD countries. The pupil-teacher ratio (excluding teacher aides) ranges from more than 20 pupils per teacher in France, Israel, Mexico and Turkey, to fewer than 10 in Chile, Iceland, New Zealand, Slovenia and Sweden (see chart below). Some countries make extensive use of teachers' aides at the ECE level.

Research demonstrates that enriched stimulating environments and high-quality pedagogy are fostered by better qualified practitioners and that better quality pedagogies facilitate better learning outcomes (OECD, 2012a). Qualifications are one of the strongest predictors of staff quality. It is important to note, however, that it is not the qualification level per se; it is related to how much specialised and practical training is included in initial staff education, what types of professional development and education are available to and taken up by staff, and how many years of experience staff have accumulated.

It is also important to note that working conditions can influence the satisfaction of professionals with their workplace, which is likely to affect the ability and willingness of professionals to provide stable relationships and attentive interactions with children (OECD, 2012a). High turnover disrupts the continuity of care, negates professional development efforts, harms overall quality and negatively affects child outcomes.

\section{Ratio of pupils to teaching staff in early childhood education (2010) Public and private institutions}

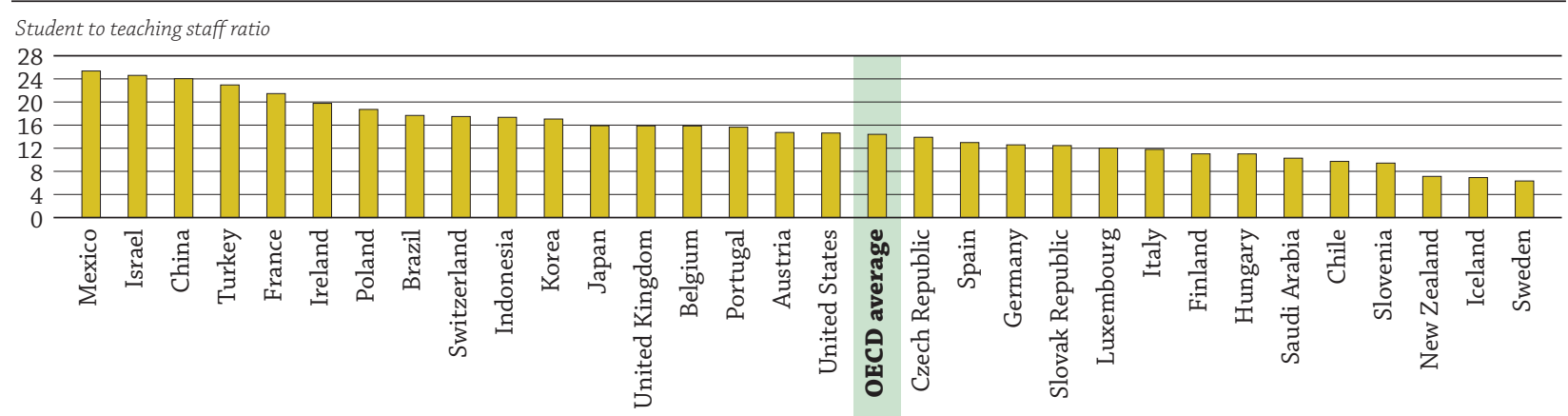

Countries are ranked in descending order of students to teaching staff ratios in early childhood education.

Source: OECD. China and Indonesia: UNESCO Institute for Statistics (World Education Indicators programme). Saudi Arabia: UNESCO Institute for Statistics. Education at a Glance 2012: OECD Indicators, Indicator C2 (www.oecd.org/edu/eag2012).

\section{The duration of participation in ECE matters too. In a majority of OECD countries, at least one year of ECE is offered for free.}

Duration is another important indicator for better learning outcomes in the later stages of life (OECD, 2010). To ensure a certain length of participation in ECE programmes, countries often provide legal entitlements to ensure access to affordable, high-quality ECEC. Many countries have started to offer "free" ECEC or ECE services to certain age groups, usually one or two years before the start of compulsory schooling. For example, the Netherlands provides free ECE for 4 and 5 year-olds, and in England and Scotland it is free for 3- and 4-year-olds. Some countries have extended this right to cover younger children as well: France, Israel, Mexico, Portugal and Sweden provide free ECEC or ECE to all 3 to 6 -year-olds.

Another policy option to extend the duration of ECE is to lower the age of compulsory education. This is often considered an effective option from an equity point of view, as inequalities are likely to exist before schooling starts and tend to grow when school is not compulsory. 
Public spending in ECEC also matters. Without sufficient public spending, there is a greater risk that access to ECEC programmes will be restricted to affluent families and that the quality of the programmes will vary.

Expenditure on ECE accounts for 9\% of OECD expenditure on educational institutions or, on average, $0.5 \%$ of overall GDP. Differences between countries are significant. For example, while $0.1 \%$ or less of GDP is spent on ECE in Australia and Ireland, $0.8 \%$ or more is spent in Denmark, Iceland, Israel and Spain among OECD countries (see chart below).

Publicly-funded ECE tends to be more prevalent in the European OECD countries than in the non-European ones. Private funding varies widely between countries, ranging from $5 \%$ or less in Belgium, Estonia, Luxembourg, the Netherlands and Sweden; to $25 \%$ or more in Austria and Germany; and to over $48 \%$ in

Australia, Japan and Korea among OECD countries. In countries that do not channel sufficient public funding to cover both quantity and quality, it is likely that some parents may be more inclined to send their children to private ECEC services, which can represent heavy financial burdens (OECD, 2012b), and others may prefer to stay home, which can hinder increasing female labour force participation (OECD, 2011).

\section{Expenditure on early childhood educational institutions as a percentage of GDP (2009)} By funding source

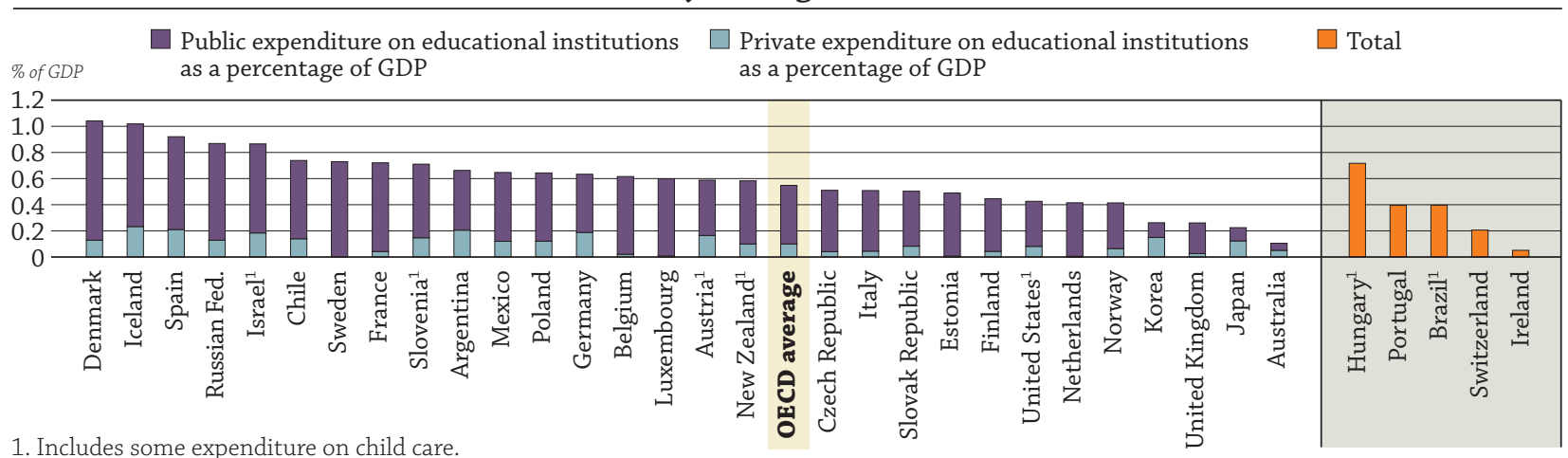

Countries are ranked in descending order of public and private expenditure on educational institutions.

Source: OECD. Argentina: UNESCO Institute for Statistics (World Education Indicators programme). Education at a Glance 2012: OECD Indicators, Indicator C2 (www.oecd.org/edu/eag2012).

\section{References}

OECD (2006), Starting Strong II: Early Childhood Education and Care, OECD Publishing, Paris.

OECD (2010), PISA 2009 Results: Equity in Learning Opportunities and Outcomes (Volume II), PISA, OECD Publishing, Paris.

OECD (2011), Doing Better for Families, OECD Publishing, Paris.

OECD (2012a), Starting Strong III - A Quality Toolbox for ECE and Care, OECD Publishing, Paris.

OECD (2012b), Education at a Glance 2012: OECD Indicators, OECD Publishing, Paris.

\section{The bottom line In an era of fiscal consolidation, ensuring access to high-quality ECEC} should remain a priority for improving children's outcomes and long-term efficiency gains for society at large, and the most vulnerable should be protected.

\section{Visit:}

www.oecd.org/edu/ earlychildhood/toolbox

www.oecd.org/edu/ earlychildhood

www.oecd.org/els/ family/database

\section{See:}

OECD (2012a), Starting Strong III - A Quality Toolbox for ECE and Care, OECD Publishing, Paris. OECD (2012b), Education at a Glance 2012: OECD Indicators, OECD Publishing, Paris.

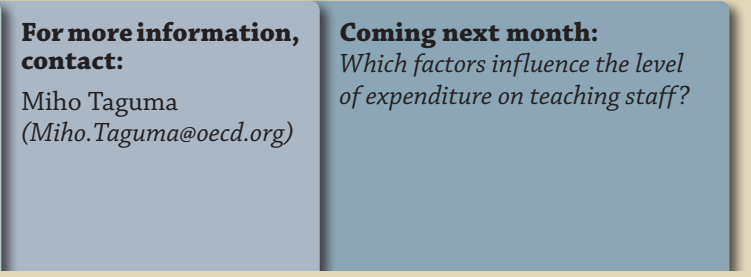

Photo credit: @ Ghislain \& Marie David de Lossy/Cultura/Getty Images 